\title{
ARTICLE OPEN \\ Long-lead ENSO control of the boreal summer intraseasonal oscillation in the East Asian-western North Pacific region
}

\author{
Hai Lin (iD ${ }^{1}$
}

The boreal summer 30-60-day intraseasonal oscillation (ISO) in the East Asian-western North Pacific (EAWNP) region strongly influences persistent heavy rainfall in East Asia and tropical cyclone activities in the tropical western Pacific. In this study, we show that there exists a significant interannual south-north shift of the EAWNP-ISO activity between the equatorial eastern Indian Ocean -Maritime continent region and the subtropical South China Sea-western Pacific. This is reflected by the year-to-year changes in the occurrence frequency of individual ISO phases that correspond to different latitudinal locations of the convection anomaly. This interannual shift is largely controlled by the El Niño-Southern Oscillation (ENSO) in the preceding winter and spring. Following an El Niño event, the ISO convective activity tends to occur in the equatorial eastern Indian Ocean-Maritime continents, whereas after a La Niña, frequent ISO-related precipitation occurs in the region of south China and the subtropical South China Sea-western Pacific. This result implies long-lead predictability for the occurrence of the summertime EAWNP-ISO activity and its associated weather.

npj Climate and Atmospheric Science (2019)2:31 ; https://doi.org/10.1038/s41612-019-0088-2

\section{INTRODUCTION}

An important feature of the boreal summer intraseasonal oscillation (ISO) is its northward propagation in the Asian summer monsoon region, ${ }^{1-6}$ which has an important impact on the weather in the highly populated East Asian region. Rainfall variability of the East Asian summer monsoon system is largely determined by the northward propagating ISO. For example, the timing of the active and break of the Asian monsoon as well as precipitation associated with the Mei-Yu in central China are influenced by the ISO. ${ }^{7-9}$ The ISO in the western North Pacific region can modulate the subtropical high variability and typhoon activity. ${ }^{10,11}$ The EAWNP-ISO activity is closely associated with heavy rainfall in south China, ${ }^{12-14}$ and tropical cyclone activity in the tropical western Pacific. ${ }^{15-18}$ Besides its local impact, the East Asian monsoon variability has a far-reaching influence on the global atmospheric circulation through teleconnections. ${ }^{19-21}$ It is clear that a close monitoring and a skilful forecast of the ISO in the EAWNP region are of great societal and economical importance.

The boreal summer EAWNP-ISO undergoes a significant interannual variability. This usually leads to year-to-year changes in frequency of tropical cyclone, ${ }^{18}$ total precipitation, ${ }^{22}$ and the date of Mei-Yu onset. ${ }^{9}$ The El Niño-Southern Oscillation (ENSO) has been identified as an important driver for the ISO interannual variability in previous studies. For example, the western Pacific ISO intensity was found to be strong during an El Niño developing summer, but weak in an El Niño decaying summer. ${ }^{23,24}$ The ENSO modulation of ISO intensity depends on the ISO time scale and location. ${ }^{25,26}$ A correlation between the northward propagating ISO in the East Asian summer monsoon region $\left(22.5^{\circ}-45^{\circ} \mathrm{N}\right)$ and the preceding winter ENSO was reported. ${ }^{27}$ It was found that during El Niño summers, the western North Pacific ISO is dominated by a higher-frequency oscillation of around 20-40 days, whereas during La Niña summers the ISO is dominated by a lower-frequency of around 40-70 days. ${ }^{25}$ However, questions remain such as what is the dominant mode of EAWNP-ISO interannual variability, how the ISO in the East Asian summer monsoon region is associated with the northward propagation of the tropical ISO, and what is the mechanism for the ENSO influence of EAWNP-ISO.

In this study, we aim to address the above questions. We show that the EAWNP-ISO activity undergoes a strong interannual variability of its location of preferred occurrence, which is strongly controlled by ENSO in the preceding seasons. This would provide an important source of skill for seasonal predictions of persistent heavy rainfall and tropical cyclone activities.

\section{RESULTS}

Shown in Fig. $1 \mathrm{a}$ is the 38-summer average and standard deviation of the frequency of occurrence for all eight EAWNP-ISO phases (aee the Methods section). It can be seen that phases 2-3 and 7-8 have a relatively high frequency of appearance, consistent with previous studies. ${ }^{9,28}$ Phases 2 and $7-8$ have a relatively large interannual variability (Fig. 1a red bars). As shown in Fig. 2, in the ISO phases 2-3 the enhanced convection occurs in the eastern Indian Ocean-Maritime continents, while in phases 7-8 the convection is located in the subtropical South China Sea-western Pacific. This indicates that the EAWNP-ISO has a relatively large year-to-year variability in these two regions.

Figure $1 \mathrm{~b}$ illustrates the leading EOF mode (EOF1) of the frequency of occurrence, which accounts for $39 \%$ of the total variance and is well separated from the other EOF modes according to the sampling error criterion. ${ }^{29}$ As can be seen, the dominant mode is characterized by an out-of-phase relationship between EAWNP-ISO phase 2 and phase 7. This indicates an interannual shift of occurrence frequency of EAWNP-ISO

\footnotetext{
${ }^{1}$ Recherche en Prévision Numérique Atmosphérique, Environment and Climate Change Canada, Dorval, QC, Canada

Correspondence: Hai Lin (hai.lin@canada.ca)
}

Received: 19 February 2019 Accepted: 12 August 2019

Published online: 02 September 2019 

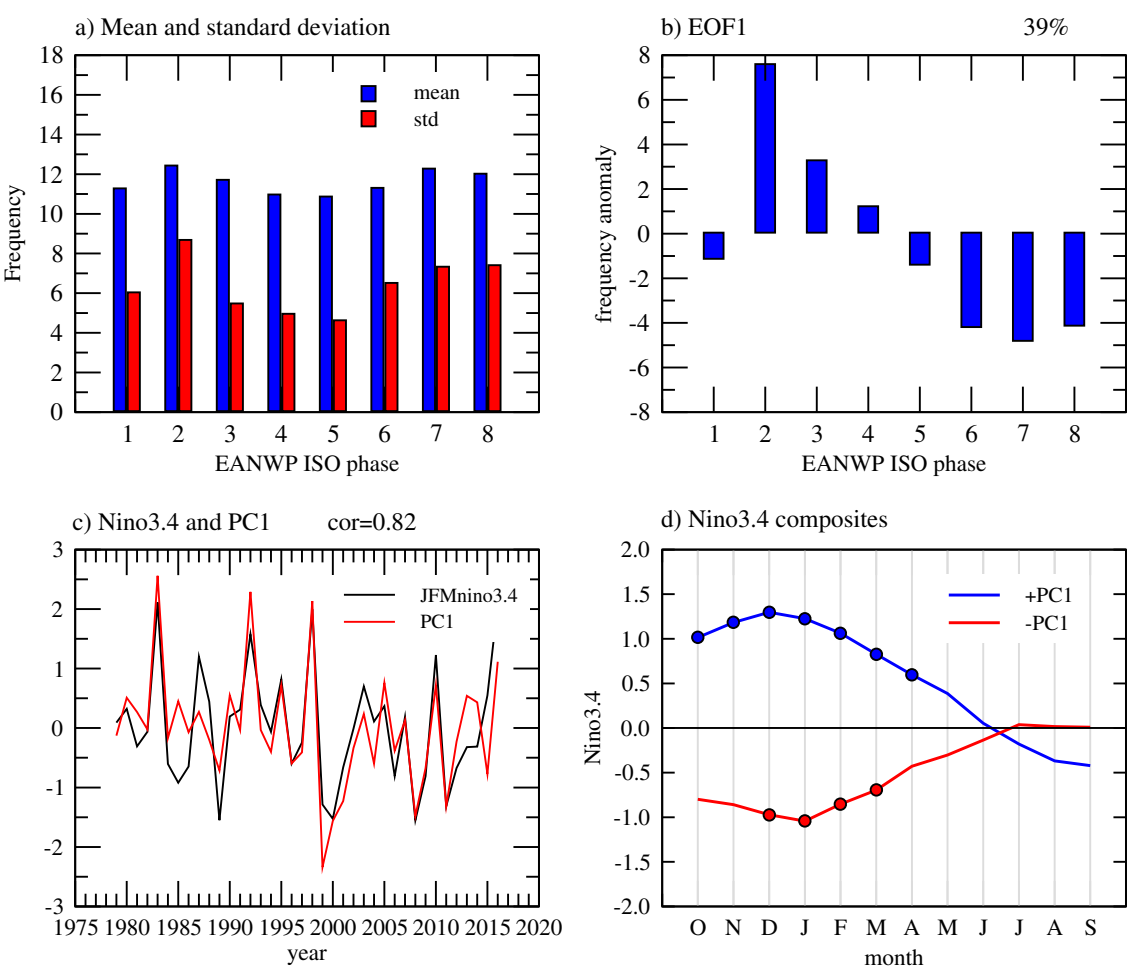

Fig. 1 a Climatological values (blue bars) and standard deviations of interannual variability (red bars) of occurrence frequency for different EAWNP-ISO phases in May-September; $\mathbf{b}$ the distribution of occurrence frequency for the leading EOF mode, represented as regression of the occurrence frequency onto PC1. The magnitude corresponds to one standard deviation of PC1; C PC1 time series (in red) and the JFM mean Nino3.4 index (in black), and (d) composites of monthly Nino3.4 index preceding the summer with PC1 $>0.5$ (in blue) and PC1 $<-0.5$ (in red). The solid circles indicate that the composite is statistically significant at the 0.01 level according to a Student's $t$-test

convection between the equatorial region of the eastern Indian Ocean-Maritime continents and the subtropical South China Sea -western Pacific.

Shown in Fig. 1c in red curve is the time evolution of the principal component of EOF1 (PC1), which is normalized by its standard deviation. Strong interannual variability can be observed. Figure $3 a$ compares the northward propagation feature of the EAWNP-ISO for strong positive and strong negative PC1 summers, where lagged regressions of zonally averaged OLR anomaly of $90^{\circ}-150^{\circ} \mathrm{E}$ with respect to that at the equator are plotted for summers with $\mathrm{PC} 1>0.5$ and $\mathrm{PC} 1<-0.5$, respectively. The zonal range of $90^{\circ}-150^{\circ} \mathrm{E}$ is the same as that used to define the EAWNPISO index. ${ }^{28}$ Both the positive and negative PC1 cases have 10 summers selected. As is seen, the behavior of the EAWNP-ISO is different between the positive and negative PC1 summers. During positive PC1, the northward propagation of the ISO convection is confined to south of $20^{\circ} \mathrm{N}$. This reflects the fact that there is a strong preference of ISO for phase 2 during positive PC1 (Fig. 1c). On the other hand, during negative PC1, the EAWNP-ISO northward propagation is much stronger and reaches farther north to $30^{\circ} \mathrm{N}$. This indicates that in positive PC1 summers, the ISO tends to stay in the tropical Indian Ocean and Maritime continents area, whereas in negative PC1 summers, the EAWNP-ISO can propagate further north and influence the weather in south China.

The frequency of occurrence of the ISO-related convection in specific locations may also determine the distribution of summertime mean convection and total precipitation. Shown in Fig. $3 c$ is the difference of composites of May-September averaged OLR anomaly between positive PC1 and negative PC1. In positive (negative) PC1 summers, the summertime averaged convection activity is enhanced (reduced) in the equatorial eastern Indian Ocean and suppressed (enhanced) in the western Pacific region around $15^{\circ} \mathrm{N}$.
ENSO is a strong interannual variability signal, which influences the ISO by changing its background basic state. To investigate the relationship between the interannual variability of the EAWNP-ISO and ENSO, composites of Nino3.4 index are calculated for positive and negative PC1 years. As the peak season of ENSO is in boreal winter, the composite is made for the months preceding the summer ISO season. A Student's t-test is performed for the null hypothesis of a zero composite. As shown in Fig. 1d, statistically significant positive Nino3.4 index is observed for positive PC1 years in the preceding months from October to April, with the maximum value in December. For negative $P C 1$, significant negative Nino3.4 index is seen from the preceding December to March with the strongest value in January. To better visualize this association, the Nino3.4 index averaged in January, February, and March is plotted in Fig. 1c in black curve, which matches very well with the PC1 time series (red curve). The correlation coefficient between these two time series reaches 0.82 . This clearly indicates that the dominant mode of summertime ISO frequency is largely controlled by the ENSO activity in the preceding winter and spring.

An important question to ask is how ENSO controls the EAWNPISO variability. Previous studies ${ }^{30,31}$ have demonstrated that El Niño (La Niña) in boreal winter influences the East Asia climate through a Pacific-East Asian teleconnection, which is linked by a lower-tropospheric anticyclonic (cyclonic) anomaly in the western North Pacific as a Rossby wave response to the equatorial western Pacific suppressed (enhanced) convection. The western North Pacific circulation anomaly can then persist to the following summer. Shown in Fig. 4a is the differences of composites for May-September averaged Z850 anomaly between years with Nino3.4 index in the preceding January to March greater than 0.5 and smaller than -0.5 . Positive Z850 anomalies are seen in the western Pacific and Southeast Asia around $20^{\circ} \mathrm{N}$, consistent with what was observed. ${ }^{30}$ These positive $\mathbf{Z 8 5 0}$ anomalies result in 
Phase 1

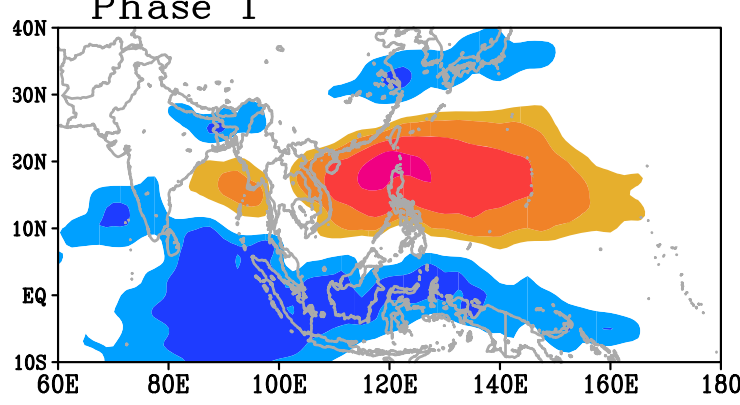

Phase 2
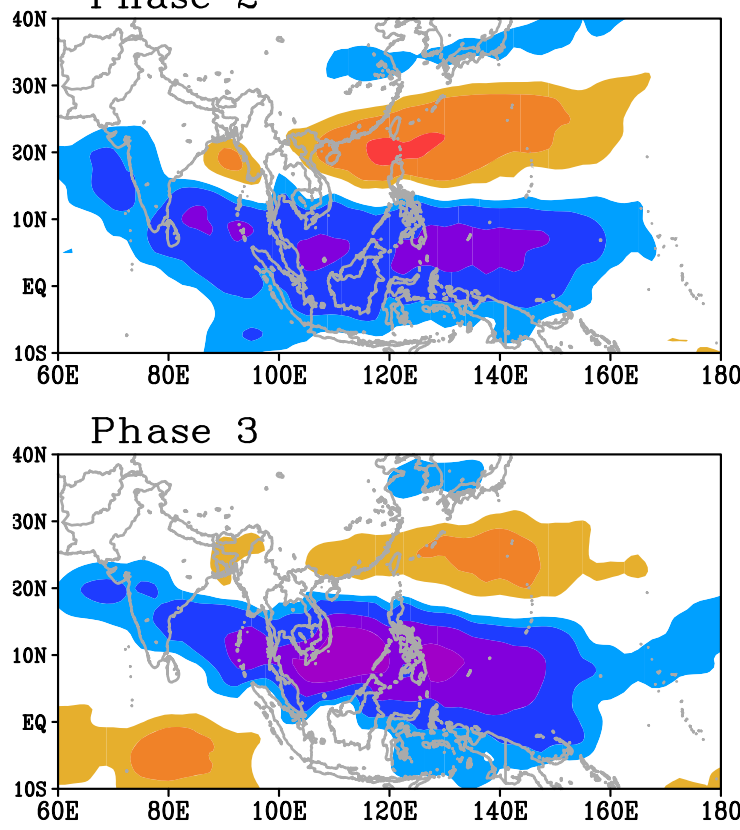

Phase 4

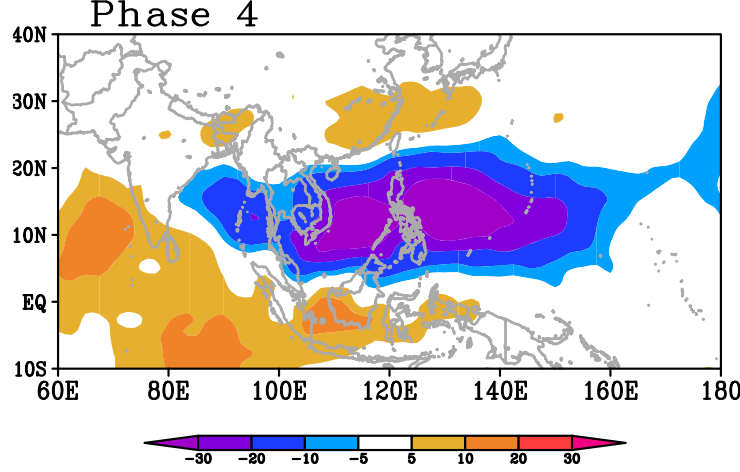

Phase 5

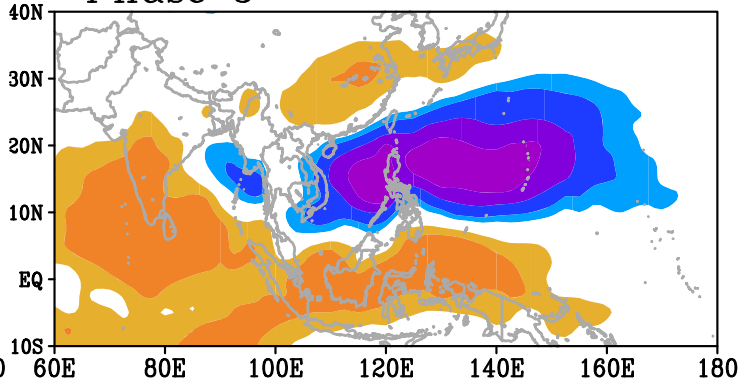

Phase 6

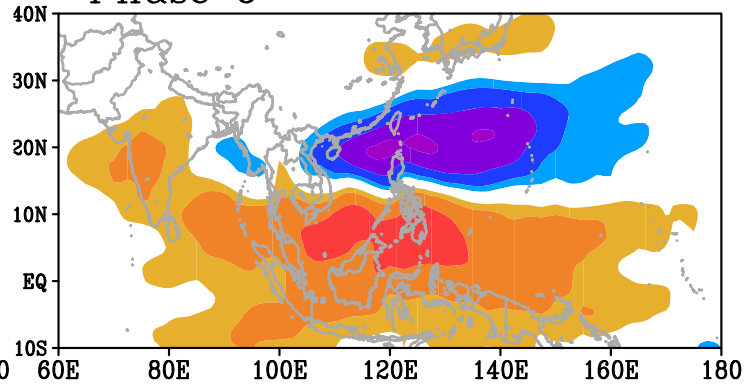

Phase 7

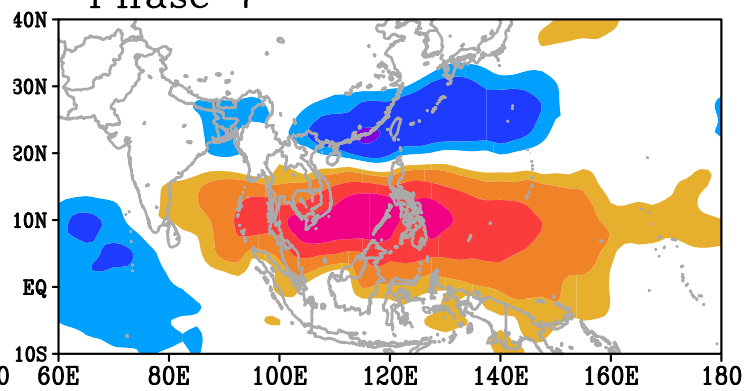

Phase 8

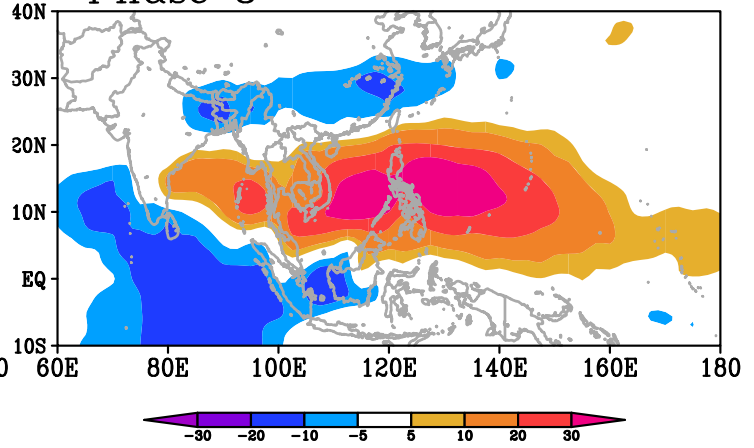

Fig. 2 Composites of OLR anomaly in the EAWNP region for different ISO phases. The unit of OLR anomaly is $\mathrm{W} \mathrm{m} \mathrm{m}^{-2}$

westward extension of the subtropical high in the western Pacific accompanied with lower-tropospheric divergence. As a result, collocated with these positive Z850 anomalies are negative anomalies of $850 \mathrm{hPa}$ specific humidity (Fig. 4b). As discussed in previous studies, ${ }^{25,32-34}$ the seasonal mean moisture field is one of the important factors for the ISO propagation. Following an EI Niño, the western Pacific subtropical anticyclonic anomaly and its associated negative moisture anomalies hinder the northward propagation of the ISO, causing the ISO convection to remain in phases 2 and 3. After a La Niña, on the other hand, the cyclonic anomaly in the subtropical western Pacific and the associated positive moisture anomalies helps the ISO to propagate northward to reach South China and the subtropical western Pacific, a location corresponding to ISO phase 7. Therefore, the interannual south-north shift of the EAWNP-ISO activity between the equatorial eastern Indian Ocean-Maritime continent region and the subtropical South China Sea-western Pacific is largely controlled by the ENSO activity in the preceding spring and summer through the Pacific-East Asian teleconnection.

\section{DISCUSSION}

This study reveals a significant interannual south-north shift of the intraseasonal oscillation activity between the equatorial eastern Indian Ocean-Maritime continent region and the subtropical South China Sea-western Pacific. This interannual variability is highly correlated with ENSO in the preceding winter and spring (a correlation of 0.82 ). This implies a long-lead predictability for 
a) Lagged OLR regression +PC1

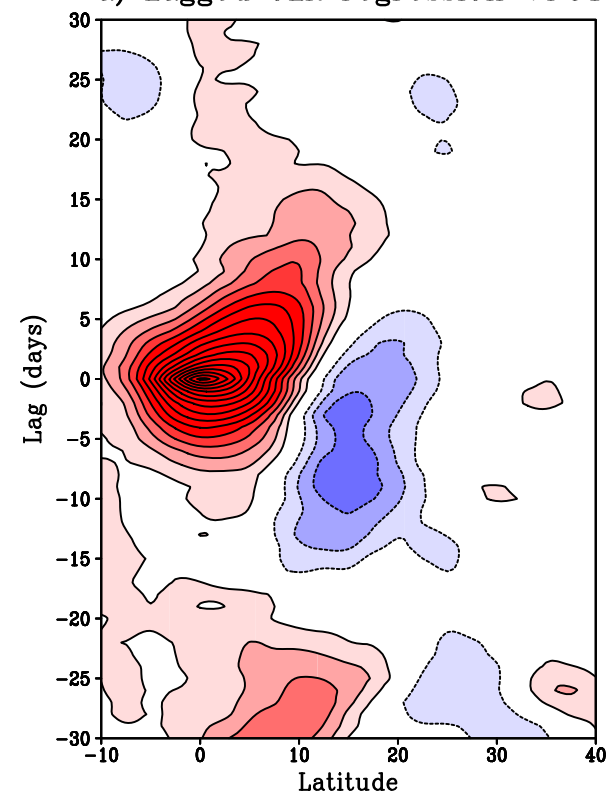

b) Lagged OLR regression $-\mathrm{PC} 1$

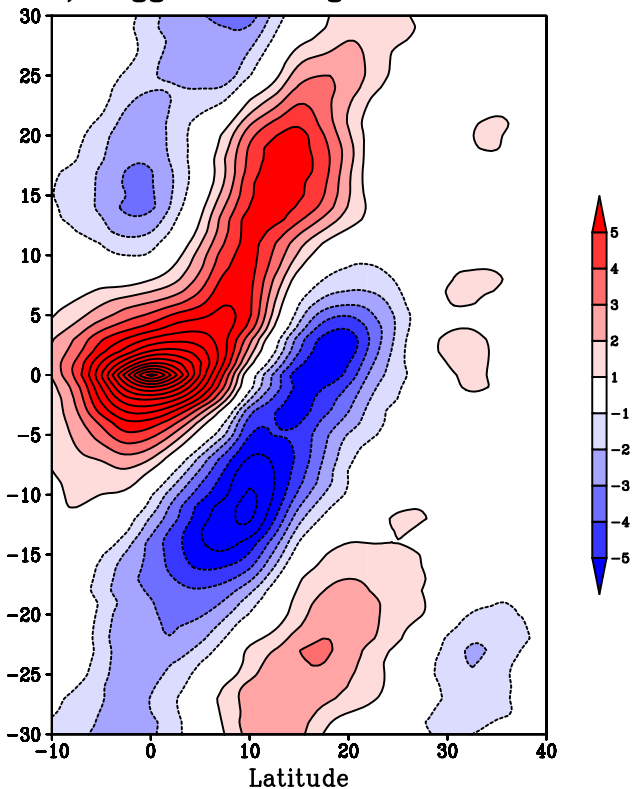

c) Compo diff OLR MJJAS PC1

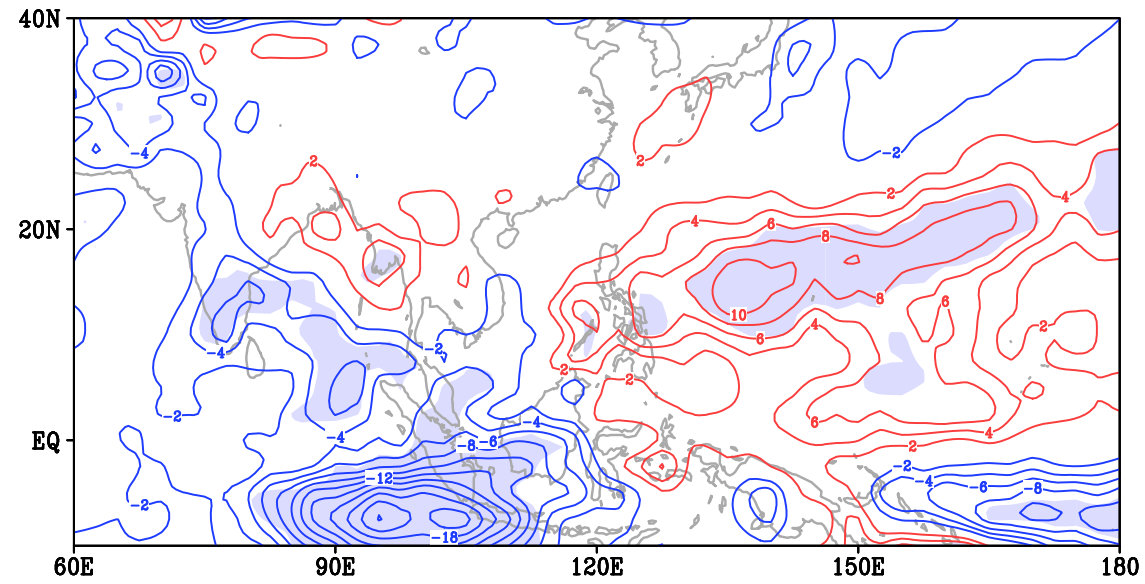

Fig. 3 a Lagged regressions of zonally averaged OLR anomaly of $90^{\circ}-150^{\circ} \mathrm{E}$ with respect to that at the equator for summers with $\mathrm{PC} 1>0.5$; b Same as a, but for summers with PC1 $<-0.5$. The OLR anomaly value corresponds to one standard deviation of that at the equator. The contour interval is $1 \mathrm{~W} \mathrm{~m}^{-2}$. The zero contour is omitted. c Difference of composites of May-September averaged OLR between positive PC1 and negative PC1. The contour interval is $2 \mathrm{~W} \mathrm{~m}^{-2}$. Contours for positive values are in read, whereas those for negative values are in blue. The zero contour is omitted. The shaded areas indicate that the value is different from zero at a significance level of 0.05 according to a Student's $t$-test

the ISO and its associated persistent heavy rainfall and tropical cyclone activities in the East Asian and western North Pacific region.

As shown in Fig. 3, stronger northward propagation of the ISO occurs during summers when PC1 is negative than in summers when PC1 is positive. Negative (positive) PC1 likely follows a La Nina (EI Nino) winter and spring, indicating that the ISO northward propagation is possibly determined by ENSO and predictable several seasons in advance. The ISO northward propagation likely influences the subseasonal to seasonal (S2S) forecast skill. This implies that the summertime S2S forecast skill in the East Asian and western North Pacific region is also closely related to ENSO.

\section{METHODS}

The data used in this study include the daily averaged values of $850 \mathrm{hPa}$ geopotential height (Z850) and specific humidity (SHUM850), and zonal wind (U850) of the NCEP/NCAR reanalysis, ${ }^{35}$ and the outgoing longwave radiation (OLR) from the National Oceanic and Atmospheric Administration (NOAA) polar-orbiting series of satellites. ${ }^{36}$ The data cover the period of 38 years from 1979 to 2016. The analysis is performed for the ISO in the extended boreal summer season of 153 days from May 1 to September 30 .

The OLR anomalies that are used to produce Fig. 2, Fig. 3a, b are obtained following the same steps as described in Lin. ${ }^{28}$ In brief, starting with the unfiltered daily OLR data for the whole year from 1979 to 2016, the seasonal cycle which is the time mean and first three harmonics of the daily climatology is first removed for each grid point. Then the time average of the 120 days immediately preceding each day is subtracted. By subtracting the previous 120-day average most of the interannual variability is removed. Left in the daily anomaly is variability mainly of subseasonal time scales. Finally, we select the daily anomaly data of the boreal summer period of 153 days from May 1 to September 30 to perform the analysis.

The monthly Nino3.4 index is obtained from the NOAA ESRL Physical Sciences Division website, which is based on the HadISST1 dataset. ${ }^{37}$ The Nino3.4 index is the area average of SST anomaly in the tropical Pacific $\left(5^{\circ} \mathrm{N}-5^{\circ} \mathrm{S}, 170^{\circ}-120^{\circ} \mathrm{W}\right)$ with the $1981-2010$ mean removed. 
a) Compo diff Z850 MJJAS nino34JFM

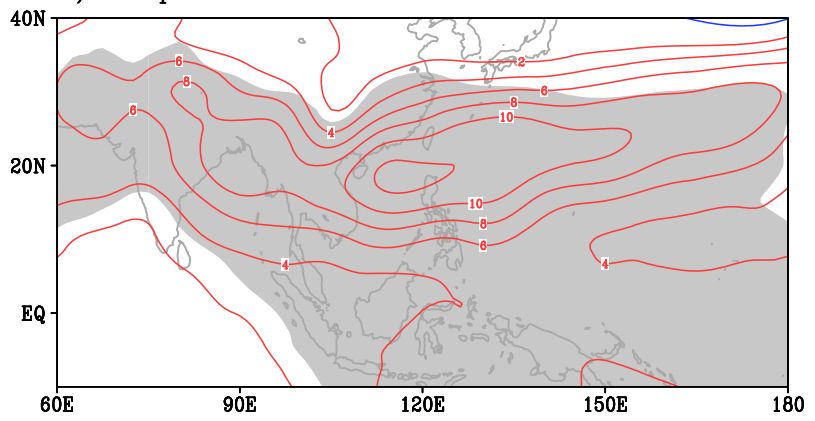

b) Compo diff SHUM850 MJJAS nino34JFM

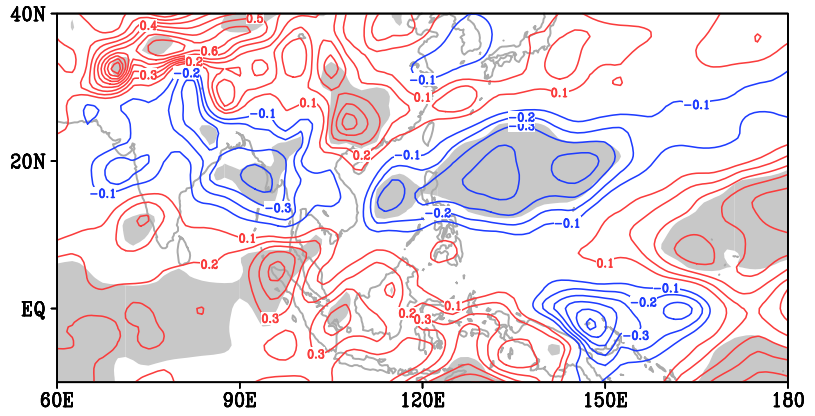

Fig. 4 Differences of composites for May-September averaged a geopotential height $\mathbf{b}$ specific humidity anomalies at $850 \mathrm{hPa}$ between years with Nino3.4 index in the preceding January to March greater than 0.5 and smaller than -0.5 . The contour interval is $2 \mathrm{~m}$ for a and $0.1 \mathrm{~g} \mathrm{~kg}^{-1}$ for $\mathbf{b}$. Contours for positive values are in red, whereas those for negative values are in blue. The zero contour is omitted. The shaded areas indicate that the value is different from zero at a significance level of 0.05 according to a Student's $t$-test

To represent the ISO in the East Asian-western North Pacific region, the EAWNP-ISO inde ${ }^{28}$ is used, which is calculated as principal components (PCs) of the two leading empirical orthogonal function (EOF) modes of the EOF analysis on the combined anomaly fields of $90^{\circ}-150^{\circ} \mathrm{E}$ zonally averaged zonal wind at 850 and OLR from $10^{\circ} \mathrm{S}$ to $40^{\circ} \mathrm{N}$. Eight phases are defined for the EAWNP-ISO corresponding to different latitudinal locations of the ISO convection (Fig. 2). This EAWNP-ISO index has been applied in previous studies to analyze the impact of subseasonal variability on persistent heavy rainfall in South China, ${ }^{12}$ tropical cyclone genesis over the western North Pacific, ${ }^{18}$ and Mei-Yu Onset. ${ }^{9}$ Different boreal summer ISO indices have been designed in the literature to represent the northward ISO propagation. ${ }^{38,39}$ The results presented here are expected to be independent of the ISO index definition.

To investigate the interannual variability of the EAWNP-ISO, we adopt an approach similar to that described in a previous study ${ }^{40}$ where the interannual variability of the Madden-Julian Oscillation ${ }^{41}$ was analyzed. Based on the phase and amplitude data of the daily EAWNP-ISO index, we count the number of days, i.e., frequency of occurrence, of each phase during each extended summer, where the days are included when the EAWNP-ISO amplitude is greater than 1.0. Different amplitude thresholds are used and the results are found insensitive to the threshold. Therefore, the frequency of occurrence is a function of ISO phase and year (Supplementary Table 1 in supplemental material). To identify the dominant phase structure of the interannual variability of the EAWNPISO, an empirical orthogonal function (EOF) analysis is performed on the frequency of occurrence. This study focuses on the first EOF mode. The second EOF (EOF2) accounts for $15 \%$ of the total variance, and shows an out-of-phase relationship between EAWNP-ISO phase 7 and phases 8/1 (Supplementary Fig. 1a). Its principal component (PC2) is illustrated in Supplementary Fig. $1 \mathrm{~b}$.

Shown in Fig. 3a, $\mathrm{b}$ are lead-lag regressions that are calculated between the OLR anomalies at the reference latitude (i.e., the equator) and those at all different latitudes in the extended summers with $\mathrm{PC} 1>0.5$ and $\mathrm{PC} 1<$ -0.5 , respectively. A negative lag $(-n)$ means that the OLR anomalies lead that at the reference point by $n$ days, while a positive lag $(+n)$ indicates that the OLR anomalies lag that at the reference point by $n$ days. The values of $n$ from -30 to 30 are used. The regression values plotted in Fig. $3 a$, $b$ correspond to one standard deviation of the OLR variability at the reference latitude, thus they have a unit of $\mathrm{W} \mathrm{m}^{-2}$.

\section{DATA AVAILABILITY}

The research presented here was derived from data sets that are all publicly available. The datasets generated during and/or analyzed during the current study are available from the author on reasonable requests.

\section{CODE AVAILABILITY}

Fortran 77 computer code was used for data processing and analysis. Computer codes are available from the author upon reasonable requests.

\section{ACKNOWLEDGEMENTS}

The NCEP/NCAR Reanalysis and OLR data were provided by the NOAA/OAR/ESRL PSD, Boulder, CO, USA, from their Website at https://www.esrl.noaa.gov/psd. The author would like to thank two anonymous reviewers for their helpful comments.

\section{AUTHOR CONTRIBUTIONS}

The author performed the analysis, interpretation of results and writing.

\section{ADDITIONAL INFORMATION}

Supplementary information accompanies the paper on the npj Climate and Atmospheric Science website (https://doi.org/10.1038/s41612-019-0088-2).

Competing interests: The author declares no competing interests.

Publisher's note: Springer Nature remains neutral with regard to jurisdictional claims in published maps and institutional affiliations.

\section{REFERENCES}

1. Yasunari, T. Cloudiness fluctuations associated with the northern hemisphere summer monsoon. J. Meteorol. Soc. Jpn. 57, 227-242 (1979).

2. Krishnamurti, T. N. \& Subrahmanyam, D. The 30-50 day mode at $850 \mathrm{mb}$ during MONEX. J. Atmos. Sci. 39, 2088-2095 (1982).

3. Wang, B. \& Rui, H. Synoptic climatology of transient tropical intraseasonal convection anomalies: 1975-1985. Meteor. Atmos. Phys. 44, 43-61 (1990).

4. Lau, K. M. \& Chan, P. H. Aspects of the 40-50 day oscillation during the northern summer as inferred from outgoing longwave radiation. Mon. Weather Rev. 114, 1354-1367 (1986).

5. Chen, T.-C. \& Murakami, M. The 30-50 day variation of convective activity over the western Pacific Ocean with the emphasis on the northwestern region. Mon. Weather Rev. 116, 892-906 (1988).

6. Hsu, H.-H. \& Weng, C.-H. Northwestward propagation of the intraseasonal oscillation in the western North Pacific during the boreal summer: structure and mechanism. J. Clim. 14, 3834-3850 (2001).

7. Chen, T.-C. \& Chen, J.-M. An observational study of the South China Sea monsoon during the 1979 summer. Mon. Weather Rev. 123, 2295-2318 (1995).

8. Hsu., H.-H., Weng, C.-H. \& Wu, C.-H. Contrasting characteristics between the northward and eastward propagation of the intraseasonal oscillation during boreal summer. J. Clim. 17, 727-743 (2004).

9. Yao, Y., Lin, H. \& Wu, Q. Linkage between interannual variation of the East Asian intraseasonal oscillation and Mei-Yu onset. J. Clim. 32, 145-160 (2019).

10. Liu, F. \& Lin, H. A study on the characteristics of the low-frequency oscillation over west Pacific and its relations with subtropical high and typhoons. Acta Meteorol. Sin. 48, 303-317 (1990).

11. Weng, C.-H. \& Hsu, H.-H. Intraseasonal oscillation enhancing C5 typhoon occurrence over the tropical western North Pacific. Geophys. Res. Lett. 44, 3339-3345 (2017).

12. Gao, J., Lin, H., You, L. \& Chen, S. Monitoring early-flood season intraseasonal oscillations and persistent heavy rainfall in South China. Clim. Dyn. 47, 1-17 (2016).

13. Hsu, P. C., Lee, J. Y. \& Ha, K. J. Influence of boreal summer intraseasonal oscillation on rainfall extremes in southern China. Int. J. Climatol. 36, 1403-1412 (2016).

14. Ren, P., Ren, H.-L., Fu, J.-X., Wu, J. \& Du, L. Impact of boreal summer intraseasonal oscillation on rainfall extremes in Southeastern China and its predictability in CFSv2. J. Geophys. Res. Atmos. 123, 4423-4442 (2018). 
15. Li, R.-C. \& Zhou, W. Modulation of western North Pacific tropical cyclone activity by the ISO. Part I: genesis and intensity. J. Clim. 26, 2904-2918 (2013).

16. Yoshida, R., Kajikawa, Y. \& Ishikawa, H. Impact of boreal summer intraseasonal oscillation on environment of tropical cyclone genesis over the western North Pacific. Sci. Online Lett. Atmos. 10, 15-18 (2014).

17. Zhao, H., Jiang, X. \& Wu, L. Modulation of Northwest Pacific tropical cyclone genesis by the intraseasonal variability. J. Meteorol. Soc. Jpn. 91, 81-97 (2015).

18. You, L., Gao, J., Lin, H., \& Chen, S. Impact of intraseasonal oscillation combination modes on tropical cyclone genesis over the western North Pacific, Int. J. Climatol. 39, 1969-1984 (2018).

19. Nitta, T. Convective activities in the tropical western Pacific and their impact on the Northern Hemisphere summer circulation. J. Meteor. Soc. Jpn. 41, 373-390 (1987).

20. Lin, H. Global extratropical response to diabatic heating variability of the Asian summer monsoon. J. Atmos. Sci. 66, 2693-2713 (2009).

21. Ding, $H$. et al. Austral winter external and internal atmospheric variability between 1980 and 2014. Geophys. Res. Lett. 43, 2234-2239 (2016).

22. Ding, Y. \& Chan, J. The East Asian summer monsoon: an overview. Meteorol. Atmos. Phys. 89, 117-142 (2005).

23. Teng, H. \& Wang, B. Interannual variations of the boreal summer intraseasonal oscillation in the Asian-Pacific region. J. Clim. 16, 3572-3584 (2003).

24. Lin, A. \& Li, T. Energy spectrum characteristics of boreal summer intraseasonal oscillations: climatology and variations during the ENSO developing and decaying phases. J. Clim. 21, 6304-6320 (2008).

25. Liu, F. et al. Modulation of boreal summer intraseasonal oscillations over the western North Pacific by ENSO. J. Clim. 29, 7189-7200 (2016).

26. Wu, R. \& Song, L. Spatiotemporal change of intraseasonal oscillation intensity over the tropical Indo-Pacific Ocean associated with El Niño and La Niña events. Clim. Dyn. 50, 1221-1242 (2018).

27. Yun, K.-S., Seo, K.-H. \& Ha, K.-J. Relationship between ENSO and northward propagating intraseasonal oscillation in the East Asian summer monsoon system. J. Geophys. Res. 113, D14120 (2008).

28. Lin, H. Monitoring and predicting the intraseasonal variability in the East Asianwestern North Pacific monsoon region. Mon. Weather Rev. 141, 1124-1138 (2013).

29. North, G. R., Bell, T. L., Cahalan, R. F. \& Moeng, F. J. Sampling errors in the estimation of empirical orthogonal functions. Mon. Weather Rev. 110, 699-706 (1982).

30. Wang, B., Wu, R. \& Fu, X. Pacific-East Asian teleconnection: how does ENSO affect East Asian climate? J. Clim. 13, 1517-1536 (2000).

31. Lau, N.-C. \& Nath, M. J. Impact of ENSO on the variability of the Asian-Australian monsoons as simulated in GCM experiments. J. Clim. 13, 4287-4309 (2000).
32. Sobel, A. \& Maloney, E. Moisture modes and the eastward propagation of the MJO. J. Atmos. Sci. 70, 187-192 (2013).

33. Jiang, X. \& Li, T. \& Wang, B. Structures and mechanisms of the northward propagating boreal summer intraseasonal oscillation. J. Clim. 17, 1022-1039 (2004).

34. Jiang, X. Key processes for the eastward propagation of the Madden-Julian Oscillation based on multi-model simulations. J. Geophys. Res. Atmos. 122, 755-770 (2017).

35. Kalnay, E. et al. The NCEP/NCAR 40-year reanalysis project. Bull. Am. Meteorol. Soc. 77, 437-471 (1996).

36. Liebmann, B. \& Smith, C. A. Description of a complete (interpolated) outgoing longwave radiation dataset. Bull. Am. Meteorol. Soc. 77, 1275-1277 (1996).

37. Rayner, N. A. et al. Global analyses of sea surface temperature, sea ice, and night marine air temperature since the late nineteenth century. J. Geophys. Res. 108, 4407 (2003).

38. Kikuchi, K., Wang, B. \& Kajikawa, Y. Bimodal representation of the tropical Intraseasonal oscillation. Clim. Dyn. 38, 1989-2000 (2012).

39. Lee, J. Y. et al. Real-time multivariate indices for the boreal summer intraseasonal oscillation over the Asian summer monsoon region. Clim. Dyn. 40, 493-509 (2013).

40. Lin, H., Brunet, G. \& Yu, B. Interannual variability of the Madden-Julian Oscillation and its impact on the North Atlantic Oscillation in the boreal winter. Geophys. Res. Lett. 2015, GL064547 (2015).

41. Madden, R. A. \& Julian, P. R. Observations of the 40-50 day tropical oscillation. Mon. Weather Rev. 112, 1109-1123 (1994).

Open Access This article is licensed under a Creative Commons c. Attribution 4.0 International License, which permits use, sharing, adaptation, distribution and reproduction in any medium or format, as long as you give appropriate credit to the original author(s) and the source, provide a link to the Creative Commons license, and indicate if changes were made. The images or other third party material in this article are included in the article's Creative Commons license, unless indicated otherwise in a credit line to the material. If material is not included in the article's Creative Commons license and your intended use is not permitted by statutory regulation or exceeds the permitted use, you will need to obtain permission directly from the copyright holder. To view a copy of this license, visit http://creativecommons. org/licenses/by/4.0/.

(c) Crown 2019 